\title{
Clean Air Journal celebrated this year's International Day of Clean Air for Blue Skies
}

\author{
Bianca Wernecke $\mathbb{~ ( i ) ~}^{1}$ \\ ${ }^{1}$ Environment and Health Research Unit, South African Medical Research Council, Doornfontein, Johannesburg, 2094 \\ https://doi.org/10.17159/caj/2020/31/2.12811
}

This year's theme for \#CleanAirDay, which is celebrated annually on 7 September, was "Healthy Air, Healthy Planet" and it aimed to emphasize the health effects of air pollution, particularly during the COVID-19 pandemic.

To celebrate the occasion on 7 September 2021, the Clean Air Journal partnered with the Environment and Health Research Unit of the South African Medical Research Council (SAMRC) to release a suite of video talks by African researchers in the air quality space who had previously published research findings in the Clean Air Journal. The five videos covered various topics relevant to Africa, ranging from household air pollution exposure and health risks to the importance of meeting National Ambient Air Quality Standards as well as the effectiveness of government policy at reducing pollution and saving people's lives. The theme of air pollution in Africa in the time of COVID-19 was also unpacked.

In anticipation of \#CleanAirDay, the Clean Air Journal and the SAMRC released one video per day for five days on their respective social media platforms (Facebook, Twitter and LinkedIn).

\section{Official teaser to the videos:}

https://youtu.be/cd7zoUqgTvg

\section{Full playlist of the videos:}

https://www.youtube.com/playlist?list=PLFdK7Ly-

ce5lptRBVEHvo4XF_G1Y-AfHG

More detail on the talks as well as the corresponding Clean Air Journal publications are as follows:

\section{Bianca Wernecke}

Many South African households burn dirty fuels (coal and wood) as the primary source of energy for heating and cooking purposes. Unfortunately, air pollution caused by these activities has a significant influence on public health and some of the people most affected are the poorest of the poor living in lowincome communities. Ms Bianca Wernecke from the SAMRC's Environment and Health Research Unit talks to us more about this. Video: https://youtu.be/Z8PwigYUzyg

CAJ article: https://www.cleanairjournal.org.za/article/view/7016

\section{Nick Okello}

Dr Nick Okello, an Environmental Scientist from Kenya, explains the different air pollution trends and their devastating effects on human health and the effectiveness of government policy

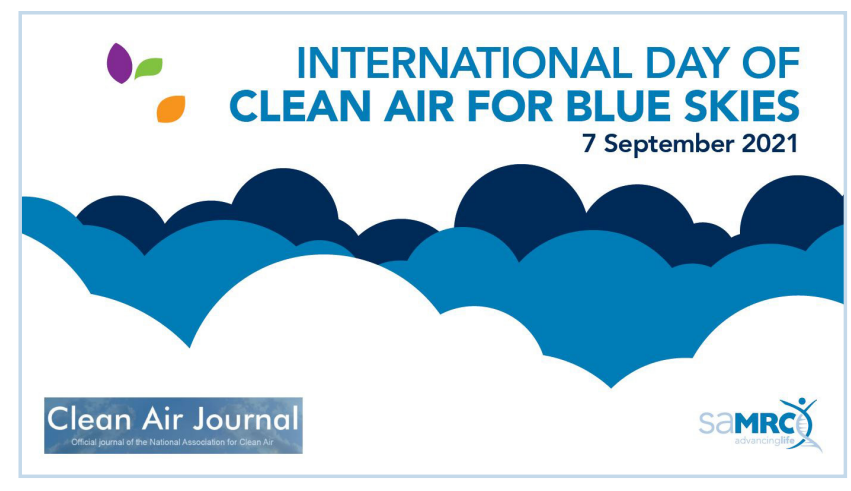

in reducing pollution and saving people's lives in Richards Bay. Video: https://youtu.be/lioMYqficQA

CAJ article: https://cleanairjournal.org.za/article/view/8012

\section{Katye Altieri}

According to $\mathrm{Dr}$ Katye Altieri, a Senior Lecturer in the Department of Oceanography from UCT, air pollution has a negative impact on human health as well the economy of any country. She explains that in order to protect human health, there is a need for effective air quality management which relies on the attainment of air quality standards. Video: https://youtu.be/V7eGQaEWuiQ

CAJ article: https://www.cleanairjournal.org.za/article/view/7005

\section{Ncobile Nkosi}

Coal is a main energy source used by many in low-income residential areas to meet basic needs, like for cooking and heating. However, it is a major source of a pollutant of concern, namely fine particulate matter. Ms. Ncobile Nkosi, a Geography Lecturer at the North-West University, talks about emission factors associated with residential burning of solid fuels using traditional cast-iron stoves. Video: https://youtu.be/D0_iEzi5hw4

CAJ article: https://cleanairjournal.org.za/article/view/6961

\section{Andriannah Mbandi}

Dr Andriannah Mbandi, a Lecturer at the South Eastern Kenya University, talks about air pollution in Africa in the time of COVID-19: the air we breathe indoors and outdoors. Her commentary on this subject was published in the Clean Air Journal. Video: https://youtu.be/oltE71NuY6o

CAJ commentary: https://cleanairjournal.org.za/article/view/8227

\section{Subtitles are available on all the videos}

